\title{
Study on Revenue Management Considering Strategic Customer Behavior
}

\author{
Chuiri Zhou', Yu Wu ${ }^{2}$ \\ ${ }^{1}$ School of Management, USTC, Hefei, China; ${ }^{2}$ School of Management, USTC, Hefei, China. \\ E-mail: zhoucr@ustc.edu.cn, gracewoo@mail.ustc.edu.cn
}

Received September $14^{\text {th }}, 2011$; revised October $20^{\text {th }}, 2011$; accepted November $18^{\text {th }}, 2011$.

\begin{abstract}
This article reviews the literatures of revenue management and introduces the status of traditional research about perishable products in this field. We analyze revenue management considering strategic customer behavior and the related researches about dynamic pricing, finally we discuss the existing problems and suggest several future research directions.
\end{abstract}

Keywords: Strategic Customer Behavior, Revenue Management, Perishable Products, Dynamic Pricing

\section{Introduction}

Littlewood rule proposed by Littlewood in 1972 is considered as the beginning of research about perishable products and service inventory management, and then it evolved into modern revenue management (RM). From the area of passenger transportation, revenue management technology covers a variety of areas, including services, manufacturing, and the growth trend continues. Revenue management adopt a certain mechanism and strategy, making supply limited and changing market demands to achieve a balance, the goal of revenue management is to make an inventory distribution in different price levels and achieve maximize revenues. The representative book in this field is The Theory and Practice of Revenue Management (Talluri and Ryzin 2005) [1], which discusses the problem of revenue management comprehensively and deeply.

Some scholars in China also have done productive work in revenue management. Professor Zhou Jing [2] expounds the model and method of revenue management. The domestic research on the revenue management mainly concentrated in the industries of shipping [3], aviation [4-5], and car rental [6] or perishable products [7-8]. Lan Boxiong and Zhang Li [9] build an optimization model of revenue management in high-speed railway line for passenger traffic. Xu Yaqing etc [10] study the revenue management problems under the situation of buyer pricing and the seller pricing respectively under the background of a famous reverse auction site, research the Ran Lun etc [11] analyses a single product dynamic pricing in a robust model.

We found that the traditional literature and practice of operation management usually consider the demand of customer as exogenous (Shen and Su, 2007) [12]. For example, assume the customer's demand as a distribution process, or specific function of price or other product attributes (for example. quality). This structure of model catches customer demand in macro levels, customers are unified and no difference. In this framework, customers are passive and don't participate in any decision-making process, customer demand is only decided by some initial assumptions of function or some distribution functions.

But in practice, customer demand is not always exogenous, customer decision making is not passive. They have more options and initiative. In economy society, customers can actively value products and then make choices. Especially in the modern society, customers can obtain the information through a lot of channels, information become much transparent, and customers become more and more shrewd. Vendors want to sell products in a high price, customers will wait for a lower price. A zero-sum game pricing decision is naturally unavoidable, vendors always improve price strategy to get as much profit as possible and customers always adjusted their purchase plan to save more money.

Customers can choose whether and when to buy the products. Vendors increasingly recognize that modern customers are willing to wait to buy the products at lower prices, namely, customers would make a choice between buying at full price in the current and waiting for future 
markdown, and we call these people as strategy customers. The consumers who are either to purchase immediately or to leave at once without buying, we call them myopic consumers [13]. Although strategic consumer behavior could potentially be a much broader concept, We shall mostly use the term "strategic customer behavior" to refer to the behavior of inter-temporal substitution behavior, when strategic customer realize the product they want to buy maybe markdown in the future, they will determine the time to purchase by considering the expectation of availability.

Ignoring the strategic customer decision-making process may have a serious consequences, Aviv and Pazgal [14] report that loss would reach to $20 \%$ because of ignoring strategic customer behavior, Besanko and Winston [15] assesses the loss of profits would as high as $60 \%$.

In recent years, strategic customer behavior aroused the attention of operation management researchers, such literature discussed revenue management theory of perishable products when facing strategies customers [12]. The authors of such literatures are scholars in international top business schools, such as the university of California, Berkeley, Carnegie Mellon university, university of Chicago, Colombia university ect, the paper mainly published in many important international operation management journal, for example, Management Science, Production and Operations Management, Operations Research, Manufacturing \& Service Operations Management.

\section{Revenue Management Strategy of Perishable Products}

Early research on revenue management considering strategic customer behavior firstly concerned about the customer's response to the seller's strategic pricing. Most of these articles assume that the company make dynamic pricing decision according to some established policies (such as EMSR or GVR policy), then they analyse strategic customer' optimal policy in this Setting. Wilson and Anderson (2006) investigate the revenue implications of this kind of strategic waiting behavior and how to set booking limits optimally. Zhou, Fan and Cho (2005) focus on the optimal purchasing strategy of a single strategic customer facing the GVR policy, they derive the threshold nature of the optimal purchasing policy and find that strategic behavior may benefit the seller. Asvanunt and Kachani (2006) formulate the customer's purchasing problem as an optimal stopping problem and derive optimal conditions from both the EMSR and the GVR pricing policies, and points out that if the seller who does not consider strategic customer behavior will cause significant loss. Because the EMSR and GVR policies are derived under the assumption of myopic customers, when the customers are strategic, this assumption will have defects.

The existing revenue management literatures facing strategic customer behavior are designed aiming at customer's strategic behavior. As Talluri and Van Ryzin [16] put forward, the model considering strategic customer behavior is fundamentally a kind of mechanism design problem. According to the view, we group the relevant literatures into following six categories.

\subsection{Dynamic Pricing}

Facing the customer's strategic behavior, researchers still focus on dynamic pricing which is the traditional revenue management strategy. However, it makes strategy design more complex as the increasingly factors influencing dynamic pricing when the customer chooses the time of purchase strategically.

One of The earliest papers which analyses optimal dynamic pricing policy about strategic customer behavior is proposed by Aviv and Pazgal [14]. They study the optimal pricing of selling limited quantity of seasonal goods to the strategic customers, the seller as Stackelberg leader announcing price, the customer as the follower deciding their purchase behavior. They proved the existence of a subgame-perfect Nash equilibrium and they assert that the equilibrium is unique when vendor's strategy is given.

Then Su [17] extended the research scope beyond price mechanism, considering the heterogeneous of customers, he find that whatever price up or down, optimal price path are dependent on customer constitutes in market. This article mainly considers the valuations and waiting cost in different customers, proving that the two together determine the optimal pricing strategy. It also point out that strategic customer behavior not necessarily hurt the seller, when supply is limited. Strategic low-valuation customer will help the seller get higher profits from strategic highvaluation one.

Elmalghraby et al. [18] investigate the optimal markdown mechanism in the presence of rational customers with multiunit demands, comparing the different optimal markdown mechanism in two different environment settings, and find the differences in seller's profits and the optimal single product price. Levin et al. [19-21] research the dynamic pricing of monopolistic company selling a perishable product to the strategic customers. Gallien [22] find that when selling limited inventory products to arriving customers in a finite period, optimal price should increase over time. Liu Xiaofeng and Huang Pei [23] study the optimal dynamic pricing strategy based on strategic customers.

\subsection{Capacity Rationing}

Sellers often cause rationing risk (inventory shortage) intentionally because the shortage threaten will motivate 
customers early buying in a high price, we call this strategy as capacity rationing. Liu and Van Ryzin [24] study a two stage capacity control model. The price in the second stage is lower than that in the first stage, the customers have different valuations to products, and they know the product price path and full rate in each stage. Through the capacity rationing, vendors can control full rate, so as to control the customer's rationing risk. Liu and Van Ryzin analyse and find that the option of capacity which can bring seller largest benefit, and they also find that the optimal capacity quantity is influenced between the price changing range and the customer's risk aversion degree level.

Zhang and Cooper [25] consider a two stage framework in which capacity rationing is observable, and prove the advantage of capacity rationing. It indicates that the seller may limit quantities in the second stage when company sells a single product through a two stage framework. Given a fixed inventory, the impact of rationing is different when price is flexible or be fixed at a certain level. For a fixed price, restricting availability at clearance price can be advantageous to the firm even when there is leftover inventory that will otherwise be wasted.

Su and Zhang [26] study how the availability of products attracts the consumers, they put forward two strategies to improve the seller's profits. One is to use commitment and the other one is to use availability guarantees. They also prove that when seller uses a combination of these two strategies can achieve optimal results. But the article assumes that the consumers are perfect rational and they form rational expectations and make optimal decisions with perfect accuracy. It is actually not inconsistent with the reality, and the article considers that the consumers should be regarded as limited rational decision makers in researches in the future.

\subsection{Posterior Price Matching (Posterior PM)}

Posterior PM policy is a market strategy which provided by seller. If the seller decreases the price within a specific period, the customer will be promised to get the price lower than the former price. The posterior PM policy can effectively change customer's buying behavior, enticing customers to buy early.

Levin et al. [19] analyses revenue management of a monopoly sellers who provide posterior price matching policy, and probes into the optimal strategy of price path and price matching. But they don't consider the strategic customer behavior.

Later $\mathrm{Xu}$ [27] study the posterior PM policy considering the strategic customers, discusses the optimum design of compensation rate. But $\mathrm{Xu}$ assume that the quantity of customer is fixed, it has not taken demand uncertainty and inventory investment decisions into account.
Assuming that vendors cannot guarantee the price path, but may practice posterior price matching strategy, Lai et al. [28] study the impact of posterior PM policy on customer purchase behavior, vendor's price, inventory strategy and expected profit. They find that the PM policy reduces the strategic customer's incentive of waiting, and allows sellers to raise prices in regular selling season. When the proportion of strategic customer is not small and product evaluation is not very low or very high over time, PM policy can greatly increase vendor's profits. The study found that this policy is insensitive to the proportion of consumers who claim the refund. This implies that a Pareto improvement for both the seller's and the customer's payoff is possible under the PM policy.

\subsection{Advance Selling}

Sellers can divide sale period into two stages, advance selling period and spot markets period. The price at two stages are different and the customers can make choice when to buy.

Tang et al. [29] discusses the advance selling strategy. At first, demand is uncertainty, retailer develops a program called an “advance booking discount” (ABD) program that entices customers to commit to their order at a discount price prior to the selling season. It improves the forecast and enables the retailer to place a more accurate order at the beginning of the selling season, which in turn reduces over-stock and under-stock costs and improves customer service levels. The article evaluates the benefits of the ABD program and characterizes the optimal discount price that maximizes the retailer's expected profit. But they did not consider customer strategy behavior.

Seller needs not only select price but also make sure providing how many products for advance selling when facing the strategic customers. Yu et al. [30] consider a seller with limited capacity who offer a single product to customers at two stages. They find that the benefit of advance selling depend on factors such as unit cost, capacity level, advance and spot market size, and customer behavior. Particularly, they analyze when the seller should order advance selling and whether advance price adds a premium or a discount to the spot price, especially as a function of available capacity and customer behavior.

\subsection{Display Formats}

An important factor should to be considered by strategic customers in the purchase decisions is the availability of product in the future, and the sales mechanism will influence the customer's estimate of product availability. Yin et al. [31] consider a retailer who sells a limited inventory of a product over a finite selling season, using one of two inventory display formats: Display All (DA) and Display One (DO). Under the DA format, the retailer 
displays all available units so that each arriving customer has perfect information about the actual inventory level. Under the DO format, the retailer displays only one unit at a certain time so that each arriving customer knows the exact about product availability but not the actual inventory level. We find that the DO format could potentially create an increasing perception of scarcity among customers, and hence it is better than the DA format.

Jerath et al. [32] also discusses the issues of product availability. They use Hotelling model comparing the benefits of using two ways, last-minute selling directly and opaque intermediary. The article argues that last-minute sales directly is preferred over selling through an opaque intermediary when consumer's valuation is high, otherwise, opaque selling will dominate. Moreover, opaque selling becomes more and more preferred over direct lastminute selling when demand increases. If there is no demand uncertainty, firms will never use direct last-minute sales.

\subsection{Quick Response Mechanism}

Quick response inventory practice (the joint of such aspects, reducing production leadtime, advanced information system and continuous demand forecast improvement) is usually applied to correct the negative influence of supply and demand mismatch. Cachon and Swinney [12] define the quick response as ability of adding inventory after updating the demand information, and further discuss the value of quick response. They divide the customers into three kinds, bargain-hunters, myopic consumers and strategic consumers.

Considering the future price, product availability and other customer behavior, sellers and customers could make optimal decision under rational expectations when they find there are strategic customers in the market. Sellers will reduce inventory and markdown, and they can control strategic customer behavior's negative effects by quick response to improve benefits.

Swinney [33] believe that the value of quick response system is generally lower with strategic customers than with myopic customers in the setting of product value is uncertainty. When product prices are fixed, the seller may reduce valuations uncertainty through advance selling, and quick response may reduce the possibility of advance selling, with rapid fulfillment capabilities, the firm loses its ability to credibly restrict inventory to create a stock-out risk, and thus may reduce its overall profitability in certain situations. Cachon and Swinney [34] take the famous fashion enterprise Zara as background context, discuss the influence of fast fashion system on strategic customer purchase behavior. This paper compares four different potential operation system: traditional systems (with standard design efforts and slow produc- tion), rapid production systems, enhanced design systems, and fast fashion systems (with both enhanced design and rapid production), and characterize equilibrium inventory levels, prices, and consumer purchasing behavior in each case. They finally find that the relationship between rapid production and enhanced design is complemented but not substituted because of multiple forces such as sales, prices, and markdown costs.

\section{Revenue Management Strategy of Durable Products}

The above revenue management object of our studies is the perishable products. And the opposite of perishable products is durable products. Durable products means the goods can be used for a long time after one purchase, such as automobile, housing, etc. One product is durable goods for consumers, but it may be perishable product for manufacturers. For instance, to the most real estate developers, because of its cost of funds and the loan repayment pressure, developers sell the housing as a perishable product while customers consider it durable goods. Another example is automobile, due to the rapid development of new technology and new car introduced continuously, each type of car has the perishable product's attributes in selling process. Durable products have perishable product's properties in sales management, we consider that we can use revenue management methods to study durable products, and in the current studies there are only small literatures study the problems of durables revenue management.

Desai et al. [35], Arya and Mittendorf [36] discuss manufacturers' revenue management of durable-goods in the presence of the strategic customers. They focus on discussing the influence of sales channel to the revenue of manufacturer. After comparing the centralized channels and decentral channels, they find that in certain conditions, the decentral channels can increase the manufacturers' profits if manufacturers could promise seller future wholesale prices. Arya and Mittendorf also consider that decentral channels will bring robust revenue relative to the manufacturer's promise.

The above researches about durable products mainly discussed how to determine the dynamic pricing in longterm selling period, they all assume that the supply of products is infinite and they don't take inventory constraint into account.

\section{Conclusions and Prospect}

The revenue management research considering strategic consumer behavior is an emerging research field, the existing researches have not been formed systematically, and many aspects need to be further developed.

First, the customer's behavior we have discussed in the 
articles is too simple, which mainly be concerned about strategic behavior, and yet there are still many other factors influencing the customer's demand and these various factors are being influenced each other. Secondly, the existing research about the design of revenue management mechanism is focused on a specific aspect of customer behavior, the theoretical research haven't formed systematically. Since revenue management is management of demand, future research can be deepened from the aspect of customer behavior. We can classify the customer's behavior motivation, and design a revenue management mechanism based on a various customer behavior motivation, which will make the revenue management mechanism designing more systematic. In addition, the research method we used needs to be improved. It has appeared experimental research method in behavioral operations management literature, yet which make theoretical research going further. However, we have not yet seen the research about revenue management mechanism based on the customer behavior till now. Because of the behavior complexity, the models established by the hypotheses need to be verified by experiments.

Revenue management is a promising field of study. Su and Zhang [26] consider that model formulating with customer behavior in all kinds of operation management studies will be a fruitful topic in the future. Dana [37] also proposed that revenue management researchers should consider creating a more accurate customer behavior model. Meanwhile, Dana believes that the research about revenue management considering customer behavior will be very exciting in the next ten years.

\section{Acknowledgements}

This work was supported by Ministry of Education PR China HCSSF(10YJC630415), USTCYF(2010) and ANSF (090416250).

\section{REFERENCES}

[1] K. Talluri and G. Van Ryzin, "The Theory and Practice of Revenue Management,” Springer, New York, 2005.

[2] J. Zhou and H. Yang, "Revenue Management Methods and Application,” Science Press, Beijing, 2009.

[3] X. Z. Bu, Q. W. Zhao and Z. Y. Wu, "Study on The Dynamic Control Policy of Container Liner Slots Based on Revenue Management," Chinese Journal of Management Science, Vol. 14, No. 1, 2006, pp. 56-60.

[4] J. Chen, Y. B. Xiao and X. L. Liu, “Joint Dynamic Seat Inventory Control for Parallel Flights with Advance Selling at Super Discount Prices," Chinese Journal of Management Science, Vol. 13, No. 1, 2005, pp. 148-152.

[5] L. Luo and J. H. Peng, "A Dynamic Pricing Model for Airline Revenue Management with Competition,” Systems Engineering-Theory \& Practice, Vol. 11, 2007, pp.
16-26.

[6] X. Cheng, "Study on Pricing and Allocation for Car Rental Based on Revenue Management," Systems Engineering-Theory Methodology Applications, Vol. 3, 2005, pp. 265-268.

[7] H. Yang and J. Zhou, "A Cournot Game of Setting Optimal Markdown Timing for Perishable Products," Chinese Journal of Management Science, Vol. 14, No. 3, 2006, pp. 45-50.

[8] Z. Z. Guan and B. S. Shi, “Ordering and Pricing Policy for Perishable Commodities Revenue Management Based on Consumer Choice Model," Systems Engineering-Theory \& Practice, Vol. 9, 2007, pp. 47-53.

[9] B. X. Lan and L. Zhang, "Revenue Management for High-Speed Passenger Railway," Chinese Journal of Management Science, Vol. 4, 2009, pp. 53-59.

[10] Y. Q. Xu, Y. H. Wei and Q. Y. Hu, "Revenue Management Problems for Customer- and Seller-Pricing Based on Priceline," Journal of Management Sciences in China, Vol. 3, 2008, pp. 63-69.

[11] L. Ran, J. L. Li and L. P. Xu, "Study on the Robust Model in Single-Unit Product Dynamic Pricing in Revenue Management," Application of Statistics and Management, Vol. 28, No. 5, 2009, pp. 934-941.

[12] S. Z.-J. Max and S. X. Ming, "Customer Behavior Modeling in Revenue Management and Auctions: A Review and New Research Opportunities," Production and Operations Management, Vol. 16, No. 6, 2007, pp. 713-728.

[13] G. P. Cachon and R. Swinney, "Purchasing, Pricing, and Quick Response in the Presence of Strategic Consumers," Management Science, Vol. 55, No. 3, 2009, pp. 497-511. doi:10.1287/mnsc.1080.0948

[14] Y. Aviv and A. Pazgal, "Optimal Pricing of Seasonal Products in the Presence of Forward-Looking Consumers," Manufacturing Service Operation Management, Vol. 10, No. 3, 2008, pp. 339-359. doi:10.1287/msom.1070.0183

[15] D. Besanko and W. L. Winston, "Optimal Price Skimming by a Monopolist Facing Rational Consumers," Management Science, Vol. 36, 1990, pp. 555-567. doi:10.1287/mnsc.36.5.555

[16] K. T. Talluri and G. J. Van Ryzin, "Revenue Management under a General Discrete Choice Model of Consumer Behavior,” Management Science, Vol. 50, No. 1, 2004, pp. 15-33. doi:10.1287/mnsc.1030.0147

[17] S. X. Ming, "Inter-Temporal Pricing with Strategic Customer Behavior,” Management Science, Vol. 53, No. 5, 2007, pp. 726-741. doi:10.1287/mnsc.1060.0667

[18] W. Elmalghraby, A. Gulcu and P. Keskinocak, "Designing Optimal Preannounced Markdowns in the Presence of Rational Customers with Multiunit Demands," Manufacturing Service Operations Management, Vol. 10, No. 1, 2008, pp. 126-148. doi:10.1287/msom.1070.0157

[19] Y. Levin, J. McGill and M. Nediak, "Price Guarantees in Dynamic Pricing and Revenue Management," Operations Research, Vol. 55, No. 1, 2007, pp. 75-97. 
doi:10.1287/opre.1060.0344

[20] Y. Levin, J. McGill and M. Nediak, “Optimal Dynamic Pricing of Perishable Items by a Monopolist Facing Strategic Consumers," Production and Operations Management, 2009.

[21] Y. Levin, J. McGill and M. Nediak, "Dynamic Pricing in the Presence of Strategic Consumers and Oligopolistic Competition,” Management Science, Vol. 55, No. 1, 2009, pp. 32-46. doi:10.1287/mnsc.1080.0936

[22] G. Gallego and O. Sahin, "Inter-Temporal Valuations, Product Design and Revenue Management," Columbia University, New York, 2006.

[23] X. F. Liu and H. Pei, "Optimal Dynamic Pricing and Inventory Policy under Strategic Customer,” Journal of Management Sciences in China, Vol. 5, 2009, pp. 18-26.

[24] Q. Liu and G. J. Van Ryzin, "Strategic Capacity Rationing to Induce Early Purchases," Management Science, Vol. 54, No. 6, 2008, pp. 1115-1131. doi:10.1287/mnsc.1070.0832

[25] D. Zhang and W. L. Cooper, "Managing Clearance Sales in the Presence of Strategic Customers," Production and Operations Management, Vol. 17, No. 4, 2008, pp. 416431. doi:10.3401/poms.1080.0039

[26] S. X. Ming and F. Zhang, "On the Value of Commitment and Availability Guarantees when Selling to Strategic Consumers,” Management Science, Vol. 55, No. 5, 2009, pp. 713-726. doi:10.1287/mnsc.1080.0991

[27] Z. Xu, “Optimal Best-Price Policy,” Northwestern University, Evanston, IL, 2008.

[28] G. Lai, L. G. Debo and K. Sycara, "Buy Now and Match Later: Impact of Posterior Price Matching on Profit with Strategic Consumers,” Manufacturing Service Operations Management, 2009.
[29] C. S. Tang, K. Rajaram, A. Alptekinoglu and J. Ou, “The Benefts of Advance Booking Discount Programs: Models and Analysis,” Management Science, Vol. 50, No. 4, 2004, pp. 465-478. doi:10.1287/mnsc. 1030.0188

[30] M. Yu, R. Kapuscinski and H.-S. Ahn, “Advance Selling with Limited Capacity and Customers’ Dependent Valuations,” Ross School of Business, University of Michigan, Ann Arbor, 2007.

[31] R. Yin, Y. Aviv, A. Pazgal and C. S. Tang, "Optimal Markdown Pricing: Implications of Inventory Display Formats in the Presence of Strategic Customers," Management Science, Vol. 55, No. 8, 2009, pp. 1391-1408. doi:10.1287/mnsc.1090.1029

[32] K. Jerath, S. Netessine and S. K. Veeraragharan, "Revenue Management with Strategic Customers: Last-Minute Selling and Opaque Selling,” Management Science, 2009.

[33] R. Swinney, "Selling to Strategic Consumers When Product Value is Uncertain: The Value of Matching Supply and Demand,” Stanford University, Working paper, 2009.

[34] G. P. Cachon and R. Swinney, "The Value of Fast Fashion: Rapid Production, Enhanced Design, and Strategic Consumer Behavior,” University of Pennsylvania, Philadelphia, 2009b.

[35] P. Desai, O. Koenigsberg and D. Purohit, "Strategic Decentralization and Channel Coordination," Marketing Economy, Vol. 2, 2004, pp. 5-22. doi:10.1023/B:QMEC.0000017033.09155.12

[36] A. Arya and B. Mittendorf, "Benefits of Channel Discord in the Sale of Durable Goods," Marketing Science, Vol. 25, No. 1, 2006, pp. 91-96. doi:10.1287/mksc.1050.0143

[37] J. D. Dana, "New Directions in Revenue Management Research," Production and Operations Management, Vol. 17, No. 4, 2008, pp. 399-401. doi:10.3401/poms.1080.0040 